\title{
MEMBANGUN BRAND AWARENESS MENGGUNAKAN STRATEGI CYBER PR \\ PADA PERUSAHAAN START-UP DI INDONESIA
}

\author{
Anindita Susilo \\ Reza Kradika Putra \\ Fakultas Ilmu Komunikasi, Universitas Mercu Buana \\ anindita.indi@gmail.com
}

\begin{abstract}
The development of technology in the era of globalization has had a huge impact on various aspects, one of which is the development of start-up companies in Indonesia. One of the pioneering companies that is developing in Indonesia is Jendela360, which is engaged in leasing apartments located in Jakarta. Although it has been present for almost 2 years, Jendela360 is still not widely known by the people of Indonesia. The results of the pre-study prove that public brand awareness of Jendela360 is still very low. This study aims to describe the PR cyber strategy used by Jendela 360 to build Brand Awareness because the activities of start-up companies are mostly carried out in cyberspace. The method used in this study is descriptive qualitative with the method of collecting data in the form of interviews. The results of this study indicate that the cyber PR strategy carried out by Jendela360 as a start up company in building its brand awareness is to improve SEO through writing, releases and posts on social media. Thus it can be concluded that Jendela360 has carried out a public relations strategy to increase its brand awareness well, starting from problem definition, program planning, action and communication, and evaluating according to the public relations strategy. further enhance programs or activities that are intended to increase brand awareness from Jendela360.
\end{abstract}

Keywords: Strategy, Cyber PR, Brand Awareness, Start-Up

\begin{abstract}
Abstrak
Perkembangan teknologi pada era globalisasi ini memberikan dampak yang sangat besar pada berbagai aspek, salah satunya adalah berkembangnya perusahaan rintisan (start-up) di Indonesia. Salah satu perusahaan perintis yang sedang berkembang di Indonesia adalah Jendela360, yang bergerak di bidang penyewaan apartemen yang berlokasi di Jakarta. Meskipun telah hadir selama hampir 2 tahun, Jendela360 masih belum banyak diketahui oleh masyarakat Indonesia. Hasil dari pra penelitian membuktikan bahwa brand awareness masyarakat terhadap Jendela360 masih sangat rendah. Penelitian ini bertujuan untuk mendeskripsikan strategi cyber $P R$ yang digunakan oleh Jendela360 untuk membangun
\end{abstract}


Brand Awareness karena aktivitas dari perusahaan start up banyak dilakukan di dunia maya. Metode yang digunakan dalam penelitian ini adalah deskriptif kualitatif dengan metode pengumpulan data berupa wawancara. Hasil dari penelitian ini menunjukkan bahwa strategi cyber PR yang dilakukan oleh Jendela360 sebagai perusahaan start up dalam membangun brand awarenessnya adalah dengan meningkatkan SEO melalui tulisan, release dan postingan di media sosial. Dengan demikian dapat disimpulkan bahwa Jendela360 telah melakukan strategi humas untuk meningkatkan brand awarenessnya secara baik, mulai dari definisi masalah, perencanaan program, aksi dan komunikasi, serta melakukan evaluasi yang sesuai dengan strategi humas. lebih meningkatkan lagi program atau kegiatan yang memang bertujuan untuk meningkatkan brand awareness dari Jendela360.

Kata Kunci : Strategi, Cyber PR, Brand Awareness, Start-Up

\section{PENDAHULUAN}

Perkembangan teknologi pada era globalisasi ini memberikan dampak yang sangat besar pada berbagai aspek, salah satunya adalah berkembangnya perusahaan rintisan (startup) di Indonesia. Berdasarkan laporan Startup Ranking, pada bulan Februari 2012 tercatat bahwa Indonesia berada pada peringkat keempat dengan start-up terbanyak, yaitu mencapai 1.705 perusahaan.

Salah satu perusahaan perintis yang sedang berkembang di Indonesia adalah Jendela360. Jendela360 adalah perusahaan startup yang bergerak di bidang penyewaan apartemen yang berlokasi di Jakarta. Jendela360 menjadi pesaing baru baik bagi agen apartemen konvensional maupun agen digital lainnya seperti rumah.com, rumah123.com, dan sewaapartemen.net. Dengan mengusung teknologi kamera $360^{\circ}$, Jendela360 menyajikan hal yang berbeda dengan startup lainnya. Meskipun telah hadir selama hampir 2 tahun, Jendela360 masih belum banyak diketahui oleh masyarakat Indonesia, khususnya DKI Jakarta.

Hasil dari pra penelitian membuktikan bahwa brand awareness masyarakat terhadap Jendela360 masih sangat rendah. Hal tersebut dibuktikan dengan kurangnya kesadaran masyarakat ketika ditanyakan mengenai Jendela360 seperti berikut: 


\section{A: Apa itu Jendela360? Perusahaan apa? Jual Jendela kah?” \\ B: Itu apa ya? Tempat furniture?}

Brand awareness menunjukkan kesanggupan konsumen (atau calon pembeli) dalam mengingat kembali atau mengenali bahwa suatu merek merupakan suatu bagian dari kategori produk tertentu (Durianto, et al, 2004: 54). Brand awareness itu sendiri adalah salah satu faktor penting yang dibutuhkan perusahaan untuk memperkuat brand produknya sebab tidak bisa kita pungkiri bahwa semakin banyak konsumen yang mengingat suatu brand, maka semakin besar popularitas brand atau perusahaan di mata masyarakat.

Banyak cara yang dapat dilakukan perusahaan untuk membangun atau meningkatkan brand awareness. Salah satunya adalah melalui aktivitas cyber $P R$ dengan menggunakan dunia maya sebagai media untuk membangun merek. Cyber $P R$ merupakan bentuk pembaharuan dari humas konvensional karena di sini kegiatan kehumasan dilakukan dengan menggunakan media baru seperti website, media sosial (Onggo, 2004:1). Sebagai salah satu agen online, Jendela360 tentunya juga merancang dan mengimplementasikan strategi cyber $P R$ sehingga dapat meningkatkan merek dan memperoleh prestasi yang membanggakan. Berdasarkan situasi tersebut peneliti tertarik untuk mendeskripsikan strategi cyber $P R$ yang telah digunakan oleh Jendela360 untuk membangun Brand Awareness. Cyber PR dipilih karena Jendela360 merupakan perusahaan startup sehingga aktivitasnya pun banyak yang dilakukan di dunia maya.

\section{TINJAUAN PUSTAKA}

Dalam suatu organisasi diperlukan suatu wadah yang khusus untuk menangani masalah yang berkaitan dengan komunikasi baik untuk publik internal maupun eksternal. Wadah tersebut adalah public relations yang bertujuan untuk menegakan dan 
mengembangkan suatu citra yang menguntungkan bagi organisasi atau instansi, terhadap sasaran publik internal dan eksternal.

Public Relations menurut Butterick (2012: 8) adalah seni dan ilmu berbagi hasil diskusi, melindungi dan menjaga berita dan informasi yang relevan tumbuh melekat pada citra, dalam kesadaran membangun reputasi. Menurut Cutlip, Center, dan Broom (2007: 30) kegiatan Public Relations dapat berjalan dengan baik dan mencapai tujuannya, maka diperlukan suatu metode tahapan atau langkah proses Public Relations yang menjadi dasar bagi strategi PR, yaitu: (1) Mendefinisikan Masalah (fact finding), (2) Perencanaan (planning), (3) Aksi dan Komunikasi (action and communication), (4) Evaluasi (evaluation).

Pengaruh teknologi komunikasi terhadap PR dapat dibentuk sebagai alat / media atau bentuk baru dari kegiatan PR, yang memunculkan istilah Cyber PR, PR Net dan aktivitas dunia virtual (Ardianto, 2010: 187). Hingga kini PR menggunakan internet sebagai sarana untuk berkomunikasi, dan banyak komunikasi dilakukan dengan menggunakan internet lebih efisien dalam waktu dan jarak tempuh. Sebagian besar kegiatan Public Relations di internet masih terbatas pada penggunaan media dalam satu arah, dar atas ke bawah untuk informasi penegakan masih menggunakan rumus komunikasi massa tradisional.

Brand awareness atau kesadaran merek, terjadi ketika masyarakat mengenal suatu produk sebagai milik perusahaan tertentu. Brand awareness terdiri dari perpaduan brand recognition (sebagai kemampuan masyarakat untuk menegaskan sesuatu yang sebelumnya sudah dijelaskan terhadap merek produk suatu perusahaan) dan brand recall (sebagai kemampuan masyarakat dalam emnamai suatu merek ketika suatu produk dibagi menajdi beberapa kategori dari kategori akan suatu kebutuhan serta kategori keinginan). Setelah masyarakat disadarkan akan keberadaan suatu merek produk tertentu maka masyarakat akan 
menajdi terbiasa dengan brand setelah mereka mendengar dan melihatnya hal ini disebut sebagai Aided Awareness.

Setelah masyarakat sering mendengar dan melihat keberadaan suatu brand maka akan secara otomatis brand tersebut berada di dalam ingatan. Yang pertama dalam pikiran masyarakat hal ini menjadi suatu produk berada dalam tahap Top-of-Mind-Awareness. Dibutuhkan pula Strategic Awareness yang terjadi apabila seseorang tidak hanya mengetahui keberadaan suatu brand namun juga mengenal bahwa ada perbedaan kualitas yang lebih baik dari produk saingannya.

Dari penjelasan tersebut Rangkuti, 2009: 40 - 41) menyimpulkan bahwa ada empat tahap pembentukan brand awareness, yaitu:

\section{Unaware of Brand}

Merupakan tingkatan yang paling rendah dalam piramida kesadaran merek, dimana konsumen tidak menyadari akan adanya suatu merek.

\section{Brand Recognition}

Tingkat minimal dari kesadaran merek. Hal ini penting pada saat seseorang pembeli memilih suatu merek pada saat melakukan pembelian.

\section{Brand Recall}

Pengingat kembali terhadap merek didasarkan pada permintaan seseorang untuk menyebutkan merek tertentu dalam suatu kelas produk, hal ini diistilahkan dengan pengingatan kembali tanpa bantuan untuk memunculkan merek tersebut.

\section{Top of Mind}

Apabila seseorang ditanya secara langsung tanpa diberi bantuan pengingatan dan ia dapat menyebutkan suatu nama merek, maka merek yang paling banyak disebutkan 
pertama kali merupakan puncak pikiran. Dengan kata lain, merek tersebut merupakan merek utama dari berbagai merek yang ada di dalam benak konsumen.

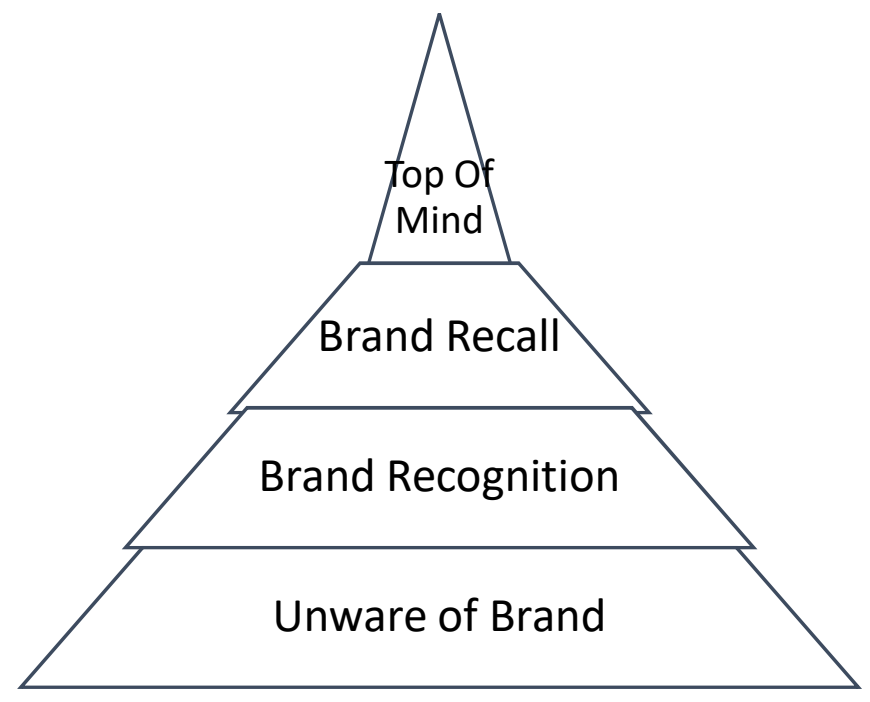

\section{Gambar 1}

Diagram Piramida Brand Awareness

\section{METODE PENELITIAN}

Penelitian ini menggunakan paradigma postpositivistik. Peneliti beranggapan bahwa paradigma ini adalah yang paling tepat digunakan karena penelitian ini mencoba menganalisis realita sosial yang ada dan menggambarkan serta mendeskripsikan bagaimana suatu komunikasi dapat terjalin dengan baik dalam sebuah organisasi. Metode penelitian yang digunakan adalah deskriptif analisis dengan pendekatan kualitatif. Dalam metode penelitian deskriptif analisis, peneliti mencoba untuk menggambarkan suatu fenomena lalu melakukan analisis dan menyajikan data secara sistematik sehingga mudah dipahami. Fenomena atau kondisi yang akan digambarkan pada penelitian ini adalah bagaimana strategi cyber $P R$ pada perusahaan start up dalam membangun brand awareness Jendela360.

Jendela360 adalah perusahaan start-up yang bergerak dibidang penyewaan apartemen di Jakarta dengan mengusung konsep virtual reality, yaitu teknologi yang memungkinkan seseorang melakukan simulasi terhadap objek nyata dengan menggunakan komputer dengan 
nuansa tiga dimensi sehingga penggunanya seolah olah terlibat secara fisik (Riyadi, et al. 2017: 76), ditambah dengan teknologi kamera $360^{\circ}$. Jendela360 dibentuk pada tanggal 1 Oktober 2016. pada awal terbentuknya Jendela360 sangat susah masuk kedalam pasar penyewaan apartemen karena masih tergolong baru apalagi dengan menggunakan teknologi kamera $360^{\circ}$ yang memang baru di masyarakat. Mereka melakukan segala cara agar bisa diterima dimasyarakat dengan bekerja sama dengan para owner unit yang menyewakan unit mereka di Jendela360.com.

Sistem penyewaan Jendela360 adalah para owner unit secara gratis menyewakan unitnya di Jendela360 tanpa dikenakan biaya apapun, tetapi apabila tersewa dari website Jendela360, pihak Jendela360 hanya mengambil keuntungan 5\% dari unit yang telah tersewa dari website Jendela360. Menggunakan prinsip mutualisme yang menjadikan Jendela360 menjadi terus berkembang, dikarenakan dapat menguntungkan semua pihak, baik penyewa dan yang menyewakan tidak dibuat sulit dengan menawarkan dari mulut ke mulut atau meminta bantuan dari pihak agen.

Subjek dari penelitian ini dibagi menjadi dua, yaitu informan utama dan informan pendukung yang terdiri dari: Kiki Guzali (CEO Jendela360), Ahmad Sopian (Humas dan Business Development Jendela360), Daniel Rannu (CTO Jendela360), Kelvin Tanu (Business Development dan Creative Media Jendela360), serta dua orang pelanggan Jendela360.

Teknik pengumpulan data yang digunakan dalam penelitian ini adalah wawancara dan observasi. Data primer akan dikumpulkan dengan menggunakan teknik wawancara mendalam (in-depth interview). Sedangkan data sekunder didapatkan dengan cara observasi dan pencarian data atau berbagai macam tulisan yang dapat dikaitkan dengan penelitian dan 
permasalahan yang bersumber dari surat kabar, majalah, jurnal, internet, buku-buku yang dapat menunjang data penelitian ini dan untuk menganalisa penelitian ini.

\section{PEMBAHASAN}

Setelah melakukan pengumpulan data melalui wawancara, peneliti menemukan bahwa Jendela360 menggunakan strategi Cyber PR dalam melakukan tindakan, atau langkahlangkah dalam program humasnya, antara lain dengan meningkatkan SEO melalui tulisan, release dan postingan di media sosial, seperti yang diungkapkan oleh salah satu narasumber:

"Kita utamakan saat itu secara powerful itu di SEO. Jadi setiap orang yang mencari sewa apartemen dan research mengatakan bahwa 90\% orang mencari apartemen pasti di google. Dan kalau misalnya mencari apartemen di Jakarta pasti akan dapat kita Jendela360) di Top 3 atau di halaman pertama. Jadi kita pastikan begitu cara kita menginformasikan bahwa ada loh Jendela360 ini”.

SEO adalah singkatan dari Search Engine Optimization. SEO sendiri sangat berpengaruh pada setiap start-up untuk dapat dikenal publik, strategi itu bisa juga berdampak hasil pencarian terutama lewat Google. Menurut CEO dari Jendela360, SEO adalah cara terbaik untuk menyebarkan informasi mengenai Jendela360 yang tidak memerlukan biaya yang terlalu banyak.

Kegiatan meningkatkan SEO ini dilakukan dengan beberapa cara, salah satunya dengan membuat artikel dan release. Pembuatan artikel dan release ini dilakukan di website Jendela360 itu sendiri dengan menggunakan kata kunci tertentu agar google dapat mencari dan menemukan artikel atau release yang telah dibuat. Cara lain adalah dengan menuliskan beberapa artikel di website Jendela360 yang terkait dengan info apartemen secara rutin di website Jendela360 serta bekerja sama dengan para blogger, media, dan juga para jurnalis online. 
Untuk mendapatkan para blogger, maka pihak Jendela360 melakukan blog walking yaitu mencari beberapa blog atau website yang sejenis dengan konten yang ada di Jendela360, konten sejenis itu seperti teknologi, tempat tinggal, dan juga tentang start-up. Selain melakukan blog walking, perwakilan dari Jendela360 juga menggabungkan diri ke perkumpulan Blogger Indonesia di Facebook dan sering berdiskusi juga di sana. Sedangkan untuk media cara yang dilakukan cukup berbeda, yaitu dengan mengontak secara personal para jurnalis / penulis yang bekerja pada redaksi atau media tertentu. Dan kontak mereka juga didapatkan secara online melalui LinkedIn.

Selain SEO, strategi Cyber PR yang dilakukan oleh Jendela360 adalah melalui event yaitu Lomba Blog yang dilaksanakan pada bulan September 2017. Tujuan dilaksanakannya lomba blog ini antara lain untuk meningkatkan posisi website Jendela360 pada search engine. Karena setiap peserta harus memasukan link yang mengarah pada website Jendela360 itu sendiri. Hal tersebut dapat dilihat apabila kita melakukan search "Sewa Apartemen" maka akan mucul website Jendela360 pada halaman 1 di google dan ada pada posisi teratas. Jadi, dapat dikatakan bahwa lomba blog tersebut dikatakan berhasil, karena dengan sedirinya website dapat menduduki peringkat 1 dalam search engine, dan dapat meningkatkan awareness juga bagi para masyarakat, atau para pemilik dan penyewa apartemen khususnya di Jakarta.

Selain dari melakukan lomba blog, melakukan publikasi melalui media sosial juga di lakukan oleh Jendela360 untuk meningkatkan brand awareness Jendela360 kepada masyarakat. Kegiatan publikasi di sosial media itu dilakukan oleh tim Business Development, yang di ketuai oleh Bapak Ahmad Sopian. Menurut Bapak Ahmad Sopian Jendela360 memiliki 4 media sosial, yaitu Instagram, Facebook, Twitter, dan Pinterest. Isi konten dari sosial media dari Jendela360 itu sendiri biasanya hanya memposting kembali apa saja yang telah di posting di blog Jendela360. Tapi tidak juga dipungkiri bahwa Jendela360 juga 
melakukan update jika ada event atau hari raya tertentu agar dapat kesan dari pada pengikut dari sosial media Jendela360

Adapun strategi tersebut dilakukan melalui tahap-tahap berikut:

\section{Definisi Masalah}

Seperti telah disebutkan sebelumnya, langkah pertama dari penentuan program humas adalah dengan mendefinisikan masalah. Dalam hal ini, Jendela360 telah melakukan langkah tersebut yaitu melalui pengumpulan fakta dengan melakukan riset di internet. Riset tersebut bertujuan untuk melihat bagaimana seseorang ingin menyewa atau mencari apartemen. Dengan demikian, hasil dari riset tersebut diketahui bahwa ada $80 \%$ orang yang mencari apartemen melalui internet dan sistem pencarian (google).

Jendela360 melihat bahwa mereka merupakan startup di bidang penyewaan apartemen yang cukup berbeda di Jakarta. Oleh karenanya mereka menginginkan bagaimana cara publik atau pemilik dan penyewa apartemen tahu tentang adanya mereka. Oleh karena itu Jendela360 meningkatkan websitenya agar dapat dilihat dan terbaca di google tersebut. Terlebih Jendela360 menandai bahwa Jendela360 adalah satu satunya startup penyewaan apartemen yang berbeda dengan menggunakan teknologi virtual reality.

Karena itulah mereka giat untuk menumbuhkan awareness publik bahwa ada salah satu startup penyewaan apartemen di Jakarta yang berbeda dengan menggunakan teknologi virutal reality. Untuk mendukung dalam meningkatkan awareness di masyarakat terutama bagi perusahaan dibidang startup maka jaringan internet sistem pencarian.

\section{Perencanaan dan Program}

Berdasarkan pada permasalahan dan hasil riset yang dilakukan oleh Jendela360 maka poin pentingnya ada pada sistem pencarian. Karena pada sistem pencarian seperti google 
tersebut merupakan salah satu cara paling tepat menurut Jendela360 untuk menumbuhkan brand awareness. Oleh karena itu Jendela360 melakukan program seperti meningkatkan SEO dan juga lomba blog

Program yang dilakukan oleh Jendela360 adalah meningkatkan SEO. Dalam meningkatkan SEO Jendela360 dapat dengan mudah mendapatkan awareness dari masyarakat. Karena setiap orang yang ingin mencari apartemen pasti mereka melakukannya di internet dan melalui google ini sesuai dengan hasil riset yang telah Jendela360 lakukan. Sehingga mereka pasti akan memilih apa yang ada di halaman pertama dari google itu sendiri. Oleh sebab itu dengan itulah mereka bisa mendapatkan awareness dari masyarakat.

Selain dari itu Jendela360 juga melaksanakan event online yaitu lomba blog. Dengan lomba blog banyak syarat syarat yang memang harus dilakuin oleh para pesertanya, syarat tersebut berdasarkan kata kunci apa yang ingin dituju oleh Jendela360 agar dapat terbaca oleh google. Event lomba blog ini ditujukan untuk para blogger yang aktif mendalami dunia blog, dan juga para blogger yang sudah mempunyai pengunjung yang memang lumayan banyak juga. Jadi, secara tidak langsung awareness dari Jendela360 ikut tumbuh di masyarakat tanpa harus menggunakan event besar.

Seluruh kegiatan itu berada di bawah naungan CEO dari Jendela360 itu sendiri yaitu Kiki Guzali. Karena berdasarkan teori dari Thomas L. Harris seluruh kegiatan dan program yang dijalankan dibutuhkan peranan langsung dari CEO atau pemegang saham.

\section{Aksi dan Komunikasi}

Pada tahap ini dikatakan adalah tahap yang cukup berbahaya, karena dapat resikonya dapat merusak citra perusahaan itu sendiri. Tetapi, Jendela360 melakukan tahap ini melalui 
media sosial mereka. Kaena Jendela360 itu merupakan startup baru jadi yang mereka utamakan adalah media publikasi yang menggunakan biaya sedikit.

Jendela360 menggunakan sosial media tersebut untuk menyebarkan info terkait Jendela360 ataupun info terkini tentang perkembangan apartemen di Jakarta. Dan juga menghubungi para media agar bisa bekerja sama untuk memuat artikel tentang Jendela360 di situs berita mereka.

Teruntuk program yang telah dijalankan seperti SEO. SEO sendiri dijalankan sudah dari awal Jendela360 itu berdiri. Karena tidak mudah untuk menaikan peringkat di SEO, butuh elemen penting seperti penulisan artikel yang menggunakan keyword tertentu, dan penulisan pada penjelasan di google.

Beda halnya dengan event lomba blog, event lomba blog dilakukan pada tanggal 25 September 2017 sampai dengan 14 November 2017. Yang bertanggung jawab atas event ini adalah team dari Business Development dari Jendela360 yang mana mencangkup divisi humas, dan content. Event ini diadakan secara online dan segala informasi disebarkan melalui sosial media seperti facebook, twitter, instagram, dan website dari Jendela360 itu sendiri.

"Salah satu alasan mengapa dipilihnya lomba blog sebagai sarana publikasi sekaligus brand awareness adalah keterbatasan dana \& biaya mengingat Jendela360 merupakan sebuah startup yang sebagian besar dananya masih menggunakan boostraping (kantong pribadi para foundernya). Namun tidak menutup kemungkinan suatu saat nanti Jendela360 juga akan terlibat dalam mensponsori suatu acara yang targeted misalnya seminar properti, event startup, dan semacamnya."

\section{Evaluasi Program}


Dalam melakukan evaluasi dari seluruh kegiatan yang dilakukan oleh Jendela360 dalam meningkatkan brand awarenessnya Jendela360 menggunakan google analytics. Bagi startup khususnya Jendela360 google analytic dapat melihat berapa orang yang sudah mengunjungi website, atau menggunakan kata Jendela360 di jaringan internet yang dibawah naungan Google tersebut.

Jendela360 melakukan evaluasi untuk kegiatan SEO dan lomba blog dengan melihat bagaimana traffic yang muncul setelah mereka melakukan kegiatan tersebut. Untuk SEO dapat dilihat setiap hari, karena hampir setiap hari Jendela360 melakukan update seperti mengeluarkan artikel, membuat rilis, dan melakukan update di sosial media mereka. Dan itu bisa dilihat apakah berdampak secara langsung atau tidak, karena di setiap artikel dan rilis harus ada kata kunci yang dituju sehingga banyak masyarakat yang membaca dan secara tidak langsung mengetahui tentang Jendela360.

Untuk lomba blog sendiri dilakukan pada akhir periode, yaitu pada saat selesai mereka melihat bagaimana visitor dari website apakah naik atau tidak. Dan bisa dilihat juga berapa orang yang telah mengklik kata "Jendela360" atau "sewa apartemen".

Hasil dari semua tahapan strategi humas yang telah Jendela360 lakukan untuk meningkatkan brand awareness-nya dapat terlihat bahwa, brand dari Jendela360 masih dalam tahap Brand Recognition. Brand Recognition itu sendiri adalah tingkat minimal dari suatu brand yang mana konsumen sudah dapat mengenali brand tersebut.

\section{KESIMPULAN}

Berdasarkan hasil penelitian yang telah dilakukan, maka dapat disimpulkan beberapa hal, antara lain: 
1) Jendela360 merupakan sebuah startup baru dibidang penyewaan apartemen di Jakarta yang cukup berbeda, karena menggunakan teknologi virtual reality sebagai fasilitas untuk para pelanggannya. Hal itu bisa menjadi keunggulan bagi Jendela360 untuk dapat menjadi startup yang mudah dikenal di masyarakat dan mudah juga membangun brand awarenessnya di masyarakat

2) Jendela360 telah melakukan strategi humas untuk meningkatkan brand awarenessnya secara baik, mulai dari definisi masalah, perencanaan program, aksi dan komunikasi, serta melakukan evaluasi yang sesuai dengan strategi humas.

Dengan makin banyak munculnya perusahaan startup di tahun selanjutnya, maka peneliti menilai penting untuk dilakukan penelitian lebih lanjut mengenai $C y b e r P R$, strategi humas, dan kegiatan humas pada perusahaan start-up lainnya.

\section{DAFTAR PUSTAKA}

Ardianto, Elvinaro. 2010. Dasar-Dasar Public Relations. Bandung: Remaja Rosdakarya.

Butterick, Keith. 2012. Pengantar Public Relations: Teori dan Praktik. Jakarta: PT. Raja Grafindo Persada

Cutlip, Scott M., Center, Allen H., and Broom, Glenn M. 2007. Effective Public Relations edisi kesembilan. Jakarta: Kencana Media Group.

Durianto, et al. 2004. Brand Equity: Strategi Memimpin Pasar. Jakarta: PT. Gramedia Pustaka Utama. 
Onggo, Bob Julius. 2004. Cyber Public Relations: Strategi Membangun dan Mempertahankan Merk Global di Era Globalisasi lewat Media Online. Jakarta: Elex Media Komputindo

Rangkuti, Freddy. 2009. The Power of Brands Teknik Mengelola Brand Equity \& Strategi Pengembangan Merek + Analisa Kasus Dengan SPSS. Jakarta: PT Gramedia Pustaka Utama.

Riyadi, Firman Setiawan, et al. 2017. Jurnal Informatika dan Komputer (JIKO) - Vol. 2, No. 2.

http://www.beritasatu.com/bisnis/478120-jumlah-startup-di-indonesia-terbanyak-keempat-didunia.html, diakses pada Senin, 23 April 2018, pukul 19.05 WIB

https://bisnisukm.com/brand-awareness.html, diakses pada Senin, 12 Juni 2017, pukul 19.05 WIB 